\title{
Understanding the Multiple Faces of Literacy: Librarian as Reading Innovator and Developer of Thinking Skills
}

\author{
Blanche Woolls \\ Professor Emerita \\ University of Pittsburgh and \\ San Jose State University \\ USA
}

\begin{abstract}
Historically, school librarians have promoted reading as a major task. In the $21^{\text {st }}$ century, a new role is evolving, that of the teacher and librarian collaborating to guide students to become information literate as well as lifelong readers and also to develop critical thinking skills. Critical thinking skills are essential. They provide students with the ability to sift through the information available to them, analyze it in relation to their past learning, and create new knowledge. To be ready for their place in a global community, students must be able to read, to know, and to do.
\end{abstract}

The role of school librarians has always been to promote reading and to inspire a love of reading. Today, we do more because our lives and the lives of our teachers and students have moved from a print-based world to one with technology in a myriad of formats. We must do more in the face of many obstacles, some old and some new, old such as lack of funding and new such as changes in teaching methodologies. The new emphasis on testing and test scores has reached a global comparison between countries to see which educational system produces students with higher achievement particularly in science and math. We are urged to accomplish more in spite of our schedules and those of our classroom teachers and administrators, all of us already too busy.

Every day teachers [and school librarians] must orchestrate a vast array of behavior, meeting many different objectives within a formidable set of constraints imposed by the building, the clock, and other human beings in the school environment. Teachers [school librarians AND administrators] should not be expected to seize on advice that will cause additional demands on their time and energy unless they are given assistance in implementing it and a rationale that convinces them it's worth the trouble. (Anderson, Evertson, and Brophy, 1988, p. 220)

In all of the discussion today, we must be aware that we have a responsibility to make it "worth the trouble" for our teachers, and most especially for our students. Our students must become not only avid readers so they continue to read as adults, but they must also be able to know and do and this requires them to be information literate with 
the ability to think critically about what they are reading, knowing, and doing. Critical thinking skills are essential if our students are to survive in a global economy. Students who become information literate will be able to exercise their literacy skills to make informed decisions about the quality and quantity of information they are reading. They can, adding this information to what they have learned in the past and what they now know, create new knowledge, but this requires using them to have the ability to exercise critical thinking skills. Students must leave our schools with the confidence that they know they can DO after they have left school.

We will begin with methods used to teach reading today and move to incentive programs and other applications of successful strategies to get students to read. We will look at what students should know and then we will discuss our role and the ways we can work with teachers to plan so students will build critical thinking skills, to be able to learn and to do. Because this is a workshop, the audience will share their best methods to get students to read for pleasure as well as for learning and for preparation for entrance exams for higher education. We will move into small groups for the next part.

For the second part of this session, we will divide by grade level or subject area and work in small groups. Using the examples of units of instruction to be provided for building critical thinking skills, additional units will be created using a template. We will divide by grade levels into small groups of 4-6 to help each other build better units. At the end session, groups will share what they have created with the entire audience.

When you return home you will have your unit to discuss with your teacher(s). You may use your experience here as an "excuse” if your teachers have been reluctant to work with you in the past. Working with teachers and the materials you have in your library, activities can be planned and carried out collaboratively. Each unit you create will serve as a model for other units. The objectives, activities, and evaluation designed in this session will build the framework for students who read to know, and to do.

We start with TO READ.

\section{To Read}

To help our students, we must first understand how reading is taught, how a basic set of reading skills is mastered. This ability t read, essential if students are to become information literate and to build creative thinking skills is predicated on the assumption 
that students can read and understand content. Returning us to our original role, to promote reading, we need to learn how teachers are teaching students to read.

The library with its resources provides the place for students not only to get reading materials and improve their literacy skills, but also to improve their critical thinking skills.

\section{Teaching Reading in Schools}

Although school librarians have always been in schools to inspire a love of reading, their efforts must support the methods teachers are expected to use to teach their students to read. Methods change but most are a rebirth of a past method with the choice, at least in the U.S. between textbooks that may have been written as readers or those containing literature as a part of the text.

Occasionally a totally new approach is offered. Beginning in the 1960s, a very labor intensive program, individualized reading, allowed students to read books from the school and public library chosen by the student because of the student's interest. They could be fiction or non-fiction, but each child read a different book. Teachers built individual spelling and writing exercises based on what students were reading. Because this took a great deal of time and teachers had large classes, most could not or would not do it. Another example is the Initial Teaching Alphabet.

This creation arrived in the U.S. from Great Britain. The 26-letter alphabet had new characters that represented the sounds, a phonics approach. It was appealing in the U.S. where we seem to rotate from teaching phonics to not teaching phonics, but it required printing reading texts with these symbols and other books did not have those symbols.

Dr. Seuss's introduction of his Cat in the Hat, an “I Can Read” book began a trend to offer "readers" that were interesting to children. Then other children's authors took up his challenge. At the same time, because of the effort to be politically correct, elementary classroom readers now had better illustrations with cross cultural children depicted and families made up of something more than a father, mother, two children, and a dog. However, children still had difficulty learning to read.

At the end of the $20^{\text {th }}$ century, whole language programs blossomed. Somewhat related to the individualized approach, this program used multiple classroom copies of 
children’s books, but they were used as "readers.” Teachers quickly developed structured worksheets that were as boring as those accompanying previous readers written by reading experts and sold by publishers in classroom sets. Considered a complete failure in most places, teachers returned to phonics. At the end of the century an added role came to the school librarian, who was asked to install a commercial reading incentive program to encourage reading by students. If volunteers do come to the library, it fell to the librarian to handle the clerical task of recording amounts read by students.

\section{Research on Effective Teaching of Reading}

An article (Taylor, Peterson, Pearson, and Rodriguez, 2002, p. 270-279) cited several research studies reflecting effective reading teachers. Three from the 1970s included such methods as maintaining an academic focus and keeping students on task, providing direct instruction, making learning goals clear, asking questions to monitor student understanding of both content and skills, and providing feedback to students about their progress. In the 1980s, one study pointed out that "effective teachers use modeling and explanation to teach students strategies for decoding words and understanding texts.”(Taylor, et al, 2002, p.270) By the mid-1990s, teachers began to stress higher level critical thinking skills and a study in 2000 showed that

compared with their less accomplished peers, more accomplished primary-grade teachers provided for small-group rather than whole-group instruction, elicited high levels of pupil engagement, preferred coaching over telling in interacting with students and engaged students in more higher level thinking related to reading. (Taylor, et al, 2002, p. 270)

In a kindergarten class Wiseman (2003, p. 802-810) observed students participating in a read-aloud session where they made predictions, related their own experiences, and manipulated the story when they sang, moved, or talked. This teacher's reading time was very noisy, and the lesson, built on the interests and concerns of the students, was developed in response to their questions. In her teaching, she helped students make connections between oral and written stories as students used crayons to write their own stories. This session is "creative, messy, collaborative, and talkative." (Wiseman, 2003, p. 802) Wiseman, as researcher, participated in the classroom teaching by writing down stories dictated by the students. 
Wiseman's further observations included the collaboration as well as the rejection of ideas of their peers. The social interaction also included students trying to do exactly what the teacher had requested of them.

The Rise of Reading Incentive Programs

Within the past ten years, the development and expansion of commercial reading programs with tests and scoring provide opportunities for teachers and the librarian to offer extrinsic rewards, pencils, pizza coupons, or the principal sharing lunch. Prizes are awarded for the number of pages or books read by students, but this process is a great deal more time and work than the simple building of a caterpillar in the school hall with each segment recording the title of a book read and the name of a student in the room.

New commercial reading incentive programs such as Accelerated Reader, Scholastic's Reading Counts, and Lexile’s Framework for Reading; Matching Readers to Text award points for answering questions about books read. They were developed to replace another reading program that moved students through levels of reading that let the good readers excel as they reached higher levels while showing the poor readers that they weren't moving as rapidly as their peers. These offer extrinsic rewards for reading, coupons for pizza, lunch with the principal, or even bigger rewards. Such programs get students to read for the prize and not for the joy of reading. It establishes the concept that one only reads when there is a reward and not because one likes to read. While there is little research to test the benefits of these programs, it would seem less likely that they would have long term benefits.

\section{How to Get Children to Read: Reading Incentives That Work}

It is possible to offer incentives to students which will offer a better chance for long term benefits. Some elementary schools offer a version of Great Books Discussion groups to encourage students to read books and discuss them. These may be led by teachers or by interested parents or other volunteers. It is also useful for students who may be less able to read. Kong and Fitch (2003, p. 352-362) recommend "Using Book Clubs to Engage Culturally and Linguistically Diverse Learners in Reading, Writing, and Talking about Books", a program in a school founded to serve immigrant children from homes where English was the second language. Student discussion of reading was at the center of the program. The teacher taught mini-lessons where she 
a) provided explicit instruction on topics of literary elements and reading responses,

b) introduced the writing prompts to help students set up purposes for the reading, and

c) provided support on composing strategies. (Kong and Fitch, 2002, p. 353)

The Book Club premise was that students should think of themselves not as individuals but as members of a learning community. The teacher gave students a list of hints: how to keep discussion moving, how to respond to questions and elaborate on responses, how to explain ideas, how to question another's interpretation, how to go beyond literal interpretations, how to ask good questions, how to take turns, and how to stay on task. Students were then given an opportunity to watch a group from the previous year in a "fishbowl" discussion demonstration.

The students’ literacy knowledge and skills were developed through guided practice. As the teacher gradually reduced her support, the students become more responsible for their learning. When she taught a new concept or task, the teacher would first introduce it to the class, have the better students model the behavior. The teacher began with something students were familiar with before going to new material. The more knowledgeable students to model so all students could then observe, participate, and ask questions; the better students could model.

According to Doiron, (2003, pp. 39-40) many children would be more easily motivated to read if they were given nonfiction books rather than always encouraging reading with fiction alone. Moss and Hendershott (2002, pp. 6-17) concur.

\section{Implications for Librarians}

A first task for librarians is to keep abreast of the reading research and share this information with administrators and teachers. As new methods are proposed, try to help everyone understand the strengths and weaknesses of the new proposals. If new reading adoptions are at a higher level than the local school, the librarian tries to understand the method and see how to fit the library program into this new method. To do this, you must understand how your teachers teach reading.

If you don't know how your teachers teach reading, you need to learn this. If at all are reluctant to have visitors to their classrooms, especially a visit from one of their peers, 
this should be done in a manner that lets the teacher know that you are truly to learn, too. Following Wiseman's model, you might volunteer to help write down dictated stories. Observation is the best way for you to learn how you may help by suggesting additional materials available in the library of which they may need to be made aware if they are to create a literary classroom.

According to Doiron (2003, p. 40), this "complicated and dynamic process to establish a literary classroom and create a teaching and learning environment that will meet all children's needs" means that teachers should have expertise in children's literature. Since teacher training programs have one course at most in the area of children's materials and very little to update this information later, your expertise is a valuable resource. You should offer in-service sessions sharing new and older materials. These should be book-talked to teachers as well as to students. Getting a time to do must be carefully planned with the principal who will also need your rational for conducting these sessions. You then must make sure that each session is appealing to teachers so they participate eagerly. You might collect posters or other giveaways you collect at conferences as incentives for their participation. While the focus may be on fiction books, you should also promote the use of fact books, and your teacher audience will be even less familiar with non-fiction titles.

Teachers can be encouraged to use fact books to motivate reading as well as fiction. Many students prefer reading about things, how to build or collect or observe things in nature. They want to learn how to take care of a new pet, how to repair an automobile, how to do magic, even cookbooks will provide reading experiences on topics that are of personal interest. Sharing "good reads" in historical non-fiction or biography is only a small step above a historical fiction book especially if it presents a time in history of interest to students. It will be very difficult to expect a student who reads a science book on nuclear energy or maintaining a website to follow the traditional outline of the obsequious book report assignment asking about plot and characters. It will be a good time for you to collaborate with teachers to improve assignments so they can't be answered with crib notes. It will make it an even shorter to moving to collaborative units of instruction. 
When teachers collaborate with the school librarian in the development of collaborative units of instruction, the winners are the students who become engaged in their own learning. They will be able to begin the creative thinking process that leads to their ability to know.

\section{To Know}

In July, 1997, the National Center for Educational Statistics published the results of their "Student Interest in National News and its Relations to School Courses," a study for the U.S. Department of Education's Office of Educational Research and Improvement. In this study, they found

In a world changing as rapidly as ours, where knowing about current events is a responsibility of every adult citizen, it is important that our adolescents develop a desire to seek and appreciate knowledge about national and world issues. This is not a necessity only for students in the United States; it is an imperative for students throughout the world. The Internet has broken down almost every barrier for communication among children and teenagers throughout the globe, and these students need to be aware of national and world issues. Because they are a part of this larger community, they must expand their horizons, recognizing that their countries cannot become or stay major players if they do not become adults prepared to take responsibility for the economic and political health of their nations.

The role of the school librarian is even more essential and goes far beyond merely collaborating with teachers. Together we must guide students to become information literate and lifelong readers, and this process incorporates techniques that help students develop critical thinking skills. Students must learn to sift through the myriads of information available to them, analyze what they find in relation to their past learning. Then they will be able to incorporate their new findings and create new knowledge with a global perspective. Finally, they must to be able to share that knowledge with their classmates now and later their colleagues in business, education, industry, health related professions and governmental agencies. It goes far beyond our assisting them to prepare reports for their teachers to assign an appropriate grade. In order for this to happen, we must learn the role of the teacher and students in relation to our role as school librarians. Teachers 
Your first obligation to teachers is to make sure they are kept aware of the current trends in education, the new methods to use to reach students. Finding research results will help them try the best teaching methods. Notifying them of new resources in your library, print and online, help them plan units of instruction. This lays the groundwork for the collaboration between teacher and librarian.

The collaboration between librarian and teacher means both think at all times about the teaching and learning process. Together they determine good teaching strategies and exciting assignments and ones that cannot be answered by cutting and pasting information. Assignments should push students into higher levels of achievement using strategies that will help students apply these strategies in all of their subjects, not just the single classroom teacher and subject content for a single assignment. At all times, assignments are designed to help students deal effectively with information in all of its formats.

Working collaboratively decisions are made concerning what students are expected to learn and the steps to be followed in the learning process. Sharing this task ensures that assignments keep students' interest high. Any learning process is easier when students are engaged in the activities. In designing the information tasks, the goal is to help students understand by studying the topic in a way that is meaningful to them. Librarians help teachers design research projects that take students out of the textbook and the process of meaningless memorization of facts. Helping in the design of projects makes it easier for everyone to understand when students are ready to proceed. Together we know when students have defined their problems and are ready to carry out their plan of action.

We librarians must also help teachers learn not to make assignments that make it easy for students to cut and paste. Teaching students to honor the work of others through appropriate citations and references is a role of the librarian working with the teacher. Battling plagiarism is a never ending role.

Librarians help teachers determine when students have achieved the desired result. We help teachers plan to evidence to collect while students are working through their information assignments so they can provide feedback to the students.

\section{Students}


Librarians, after helping students define their information needs and creating meaningful questions, show students the places available to find the best resources to answer their questions. Students must learn to access information quickly while using the variety of information gathering tools available to them. As librarians, we make sure we provide the best resources that budgets allow.

Librarians provide data from various databases with many perspectives, and they help students look at data from these different perspectives, seeing relationships and making connections. It is up to us to teach students how to select what is useful and current and recognize what is authentic, and relevant. Perhaps most important of all, students need to learn how to select only the information they need discarding the extraneous.

Students need help in learning how to record and report data they find accurately and efficiently. They need to be reminded how to write about the data using their own words. Students need to evaluate resources, sort data, to look for trends and relationships. They should be able to determine what caused a given event or phenomenon, and they should be able to predict the effect should a similar situation occur. At the end of an assignment they must be able to synthesize information in such a way that it has personal meaning in their lives.

Reviewing the information they have collected, students are encouraged to make judgments, form opinions, and draw conclusions. They need to be able to decide the potential consequences or the impact of their discoveries.

At the end of the assignment, students should be able to evaluate the strengths and weaknesses of their searches in relation to the information they located. Ultimately they must be able to set goals for their personal improvement. This means the process carries over into other classes the student takes.

Students must learn ways to share what they learn through presentations to their classmates. This may be instead of or in addition to papers or projects turned in to their teachers for grading. We have reached the point where this should be something more creative than a power point presentation. 
At the highest level, students apply learning to new situations, evaluate their own learning processes, and set new goals to improve their learning. What librarians and teachers must do to help students achieve this learning and ability to apply it, to evaluate it, and to set new goals has many steps. The first is to help teachers decide what they want their students to read, to learn and to do. New learning must be placed on past learning. Teachers may not know what students have learned and we can help them because we have worked with other teachers and other students and the entire curriculum.

Next we help them plan a basic introduction to the new topic and to make sure students can read and understand the material. Certainly we are major players here because information at different levels of reading and understanding are available in the library. Book marking web sites and database information makes it readily available for students who can access it quickly. Focusing makes it less likely they will be distracted by a different, unrelated subject.

We help build these assignments in such a way that students who are more advanced go forward rather than be bored with the introductory material. Having students work in pairs with the students who do understand can help those who are less informed. If a picture is truly worth a thousand words, using a picture to explain works. If no picture is readily available, perhaps one of the students familiar with the topic can create that picture.

School librarians suggest audiovisual materials or human resources available in the library and in the community to help set the stage. Nothing is as effective as it is to have an expert on a topic talk with students. Viewing a good video is another picture that is worth those 1,000 words. Students can be helpful to librarian and teacher in analyzing both the content and how useful a resource is and the degree of interest it will be to their classmates. They can also help each other evaluate resources.

Students need to be able evaluate resources on many levels from the very basic, "Is the information accurate," to more difficult looks to see if the information is propaganda rather than fact. Again, the school librarian teaches how to evaluate resources for authenticity and accuracy. While the Internet is 
certainly a good place for students to visit, it does not alleviate the need to look in print resources to check for accuracy in the data they find, and accuracy is sometimes defined as the difference between fact and opinion. Students should be given examples of how to check a fact as opposed to reading an opinion.

Learning how to collect and sort data are skills that students need if they are going to synthesize what they find on a topic. Organizing data and reporting it in a logical fashion means students must carefully record findings; and librarians can help the teacher in making sure students know how to create spreadsheets for their information. When students begin preparing reports, they need to learn how to display data using appropriate tables, graphs, and charts to list and show data. The school librarian should have good examples in the current media to help students see how newspapers and magazines display data for their readers. It is one way to get students interested in current events.

Students need to learn that data has a limited life span. How to find the most recent statistics is critical or they will make incorrect assumptions of the direction of a trend. They also need to be taught to check any statistic in as many sources as possible to confirm its probable accuracy.

Teacher and librarian collaborate to teach students how to look for trends and relationships in the data they find. Students should practice skimming any resource to find the points that are relevant to their search. This is particularly difficult if students are poor readers. These students are taught to use abstracts of articles before trying to find information in the article. Using the table of contents of a book will help them discard a book before even reading the introduction to the book.

Students must learn methods to analyze why events happened. The old adage that if we don't understand history, we are destined to repeat it has global applications. Assignments using current events from newspapers can be traced through historical documents to see what happened before the event being reported. Students can make "what if" analyses of situations to determine what might happen in a similar situation today. Students who review the past in relation to the present can make a prediction of things to come in the future. To do this, 
they are given assignments requiring them to make judgments, form opinions, and draw conclusions. They are encouraged to pursue whatever opinion they make so that they can draw conclusions perhaps recognizing any bias they may have toward an issue. Teaching students to synthesize information allows them to make it have personal meaning in their lives.

When the assignment is completed, the next objective is to help students recognize the strengths and weaknesses of their searches both in quality of their search strategies and in terms of what they have found. They review the steps they followed from the original outline through changes based on resources located. They the relevance, accuracy, and authenticity of the information they located, and this is particularly important when they have found information on the web.

Once their process has been confirmed, they need to be able to decide the potential consequences or the impact of their discoveries. While it may seem extremely unlikely that a student will uncover a cure for cancer or a means for world peace, one should not assume that this won't happen. Helping students seek solutions to their own problems and those of the environment in which they function is an ultimate goal.They need to recognize what they must do to be even more successful with their next assignments.

\section{To Do Means To Share}

Students must also learn ways to share what they learn through presentations to their classmates as well as papers turned in to their teachers for grading and that should be something more creative than a power point. Helping teachers make arrangements for students to report their findings in a variety of ways helps everyone. For every student or group of students to make an oral report of their findings is dulling to the point of lack of engagement with everyone including the teacher.

\section{To Do Means to Improve}

At the highest level, students learn to apply learning to new situations. To challenge students to improve situations is an ultimate assignment. As a secretary to the chief inspector in a factory in my early work career, I rode to work with three others and they often asked me to type their suggestions for the suggestion 
box. A suggestion that was implemented resulted in a bonus for that person. We are not always rewarded extrinsically for improvements we are able to achieve, but the intrinsic is often more satisfying. Give students a challenge to find a solution for problems in their school, in their community, in their city, and in their country.

When students can evaluate their own learning processes and set new goals to improve their learning, the remainder of their life in school and their later life as adults will be both more satisfying as well as more useful to the world in which they are going to live and work. It's a big assignment, but one that school librarians worldwide, understanding the multiple faces of literacy, are the most competent person in their schools to accept this assignment.

\section{References}

Anderson, L. M., Evertson, C. M. and Brophy, J. E. (April 1979). ”An Experimental Study of Effective Teaching in First-Grade Reading Groups.” Elementary School Journal. 79: 220.

Doiron, R. (January 2003). "Motivating the Lifelong Reading Habit Through a Balanced Use of Children’s Informational Books.” School Libraries Worldwide 9: 39-40.

Kong, A. and Fitch, E. (December 2002/January 2003). "Using Book Club to Engage Culturally and Linguistically Diverwse Learners in Reading, Writing, and Talking about Books,” The Reading Teacher 56: 352-362.

Moss, B. and Hendershot, J. (September 2003). “Exploring Sixth Graders' Selection of Nonfiction Trade Books.” The Reading Teacher 56: 6-17.

Taylor, B.M. and Peterson, D.S., Pearson, P.D., and Rodriguez, M.C. (November 2002). "Looking Inside Classrooms: Reflecting on the "How" As Well As the "What” in Effective Reading Instruction," The Reading Teacher 56: 270-279.

Wiseman, A.M. (May 2003) “Collaboration, Initiation, and Rejection: The Social Construction of Stories in a Kindergarten Class. The Reading Teacher 56: 802-810. 
Reproduced with permission of the copyright owner. Further reproduction prohibited without permission. 